\title{
Otmanam
}

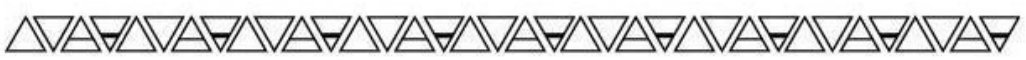

DOI 10.31418/2177-2770.2020.v12.n.34.p489-515 | ISSN 2177-2770

Licenciado sob uma Licença Creative Commons

\section{SÃO PAULO CIDADE NEGRA NO SÉCULO XXI}

\author{
Reinaldo José de Oliveira ${ }^{1}$ \\ Regina Marques de Souza Oliveira ${ }^{2}$
}

\begin{abstract}
Resumo: O texto aborda dois temas centrais na literatura sobre relações étnico raciais e espaço urbano: de um lado, os territórios e as territorialidades negras e, de outro lado, a segregação racial na cidade de São Paulo, percorrendo o contexto histórico e social do século XX e o momento atual. No decorrer do texto, dentre as observações, analiso a hierarquia das desigualdades de classe social, gênero, etnia raça e o território por intermédio da literatura da área e dos dados socioeconômicos, referente aos Censos Demográficos do IBGE, 1991, 2000 e 2010. Nas considerações finais, problematizo uma questão que diz respeito às cidades brasileiras: A segregação racial na cidade de São Paulo se manteve ou avançou?
\end{abstract}

Palavras-chave: segregação racial, território negro, política antinegritude, hierarquia das desigualdades.

\section{SÃO PAULO BLACK CITY IN THE 21ST CENTURY}

\begin{abstract}
The text addresses two central themes in the literature on ethnic racial relations and urban space: on the one hand, black territories and territorialities and, on the other hand, racial segregation in the city of São Paulo, covering the historical and social context of 20th century and the present moment. Throughout the text, among the observations, I analyze the hierarchy of inequalities of social class, gender, ethnicity, race and territory through the literature of the area and socioeconomic data, referring to the IBGE Demographic Census, 1991, 2000 and 2010. Final considerations, I problematize a question that concerns Brazilian cities: Has racial segregation in the city of São Paulo been maintained or advanced?
\end{abstract}

Keywords: racial segregation, black territory, anti-blackness policy, hierarchy of inequalities.

\section{CIUDAD NEGRA DE SÃO PAULO EN EL SIGLO XXI}

\footnotetext{
${ }^{1}$ Sociólogo, Doutor em Ciências Sociais pela PUC SP. Professor do Centro de Formação de Professores, UFRB, Campus Amargosa. Professor do IFBA, Campus Catu. E-mail: reinaldo.jose@ uol.com.br ORCID: https://orcid.org/0000-0003-3770-7862

${ }^{2}$ Psicóloga, Doutora em Psicologia Social pela PUC SP. Professora da UFR, Centro de Ciências da Saúde, Campus Santo Antônio de Jesus. E-mail: marquesregina@uol.com.br ORCID: https://orcid.org/0000-0003-3720-0922
} 


\section{Otarandusen}

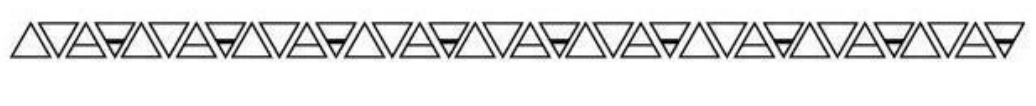

Resumen: El texto en cuestión apunta a observar las Ciudades Negras, aquí, interpretadas por ciudades pequeñas y medianas. Analizo cómo se refleja la segregación étnica racial en las ciudades pequeñas y medianas de Brasil. En el texto, inicialmente seleccioné y analicé el universo de las cien ciudades más grandes, proporcionalmente (\%), las diez ciudades más grandes con representación negra. Para comprender las desigualdades y la segregación, analicé el ingreso nominal promedio entre blancos y negros en Brasil y en ciudades seleccionadas. Entre las interpretaciones de la imagen de las ciudades pequeñas y medianas, las ciudades negras se encuentran en el noreste del país, en los estados de Maranhão y Bahía, especialmente en Bahía, en la región de Recôncavo. Hoy en día, las ciudades negras sufren un impacto de segregación étnica racial diferente de los grandes centros, debido a aspectos históricos y locales que son particulares del territorio.

Palabra clave: segregación racial, territorio negro, política anti-negra, jerarquía de desigualdades

\section{VILLE NOIRE DE SÃO PAULO AU 21E SIIECCLE}

Résumé: Le texte aborde deux thèmes centraux de la littérature sur les relations raciales ethniques et l'espace urbain: d'une part, les territoires et territorialités noirs et, d'autre part, la ségrégation raciale dans la ville de São Paulo, couvrant le contexte historique et social de 20e siècle et le moment présent. Tout au long du texte, parmi les observations, j'analyse la hiérarchie des inégalités de classe sociale, de sexe, d'ethnicité, de race et de territoire à travers la littérature du territoire et les données socio-économiques, en référence au Recensement démographique IBGE, 1991, 2000 et 2010. Considérations finales, je problématise une question qui concerne les villes brésiliennes: la ségrégation raciale dans la ville de São Paulo a-t-elle été maintenue ou avancée?

Mots-clés: ségrégation raciale, territoire noir, politique anti-noirceur, hiérarchie des inégalités

\section{INTRODUÇÃOO}

O objetivo do presente texto visa analisar a relação entre territórios negros e segregação racial na história do século XX e o momento atual da capital paulistana, tida como a principal urbe no cenário nacional.

Para melhor retratar o cenário do território e das territorialidades negras, brevemente, destaco a interpretação da pós-abolição até a nossa contemporaneidade, posteriormente, a partir das informações dos Censos Demográficos do IBGE, 1991, 2000 e 2010, observo o quadro da segregação e das desigualdades entre brancos e negros, sobretudo as políticas antinegros na capital paulistana. 
As ciências que abordam a cidade e o urbano, como a sociologia, história, geografia, arquitetura e urbanismo, iniciaram a abordagem teórico metodológica nas últimas décadas do século XX sem relacionar a categoria étnico racial (TELLES, 2003; ROLNIK, 1989). No decorrer do século passado, os espaços e lugares habitados e vivenciados pela população negra, a categoria étnico racial foi negligenciada, em razão, por exemplo, da profunda inserção do mito da igualdade na sociedade brasileira. Portanto, em boa parte do século passado, a ideia de segregação, gradativamente, foi tomando corpo no chão das cidades brasileiras.

A ausência de interpretação sobre a segregação racial gera inúmeras entraves e problemas, dentre eles, a ausência da formação em capital social, científico e tecnológico para abordar o quadro da realidade das desigualdades entre negros e brancos nas cidades brasileiras. A formação em ensino, pesquisa e extensão é central para a constituição de referências teórico metodológicas na área. É central para o debate nacional e internacional, em específico, na sociedade brasileira é imprescindível para estruturar políticas públicas nas áreas de planejamento urbano, na instalação de equipamentos públicos de consumo coletivo e para a promoção de políticas estruturais que realmente correspondam às bases das desigualdades nas cidades brasileiras, como a segregação e as desigualdades socioeconômica, étnico racial e de gênero.

Meus trabalhos que destacam o espaço social, a geografia e o território com ênfase nas relações étnicas e raciais (2002; 2008; 2015; 2016; 2018), contribuem para o desenvolvimento de uma área de estudos e pesquisas essencial para problematizar o cenário das cidades brasileiras. Não é possível afirmar categoricamente que o retrato da segregação racial esteja inscrito no chão de todas as cidades, porém, as referências iniciais reforçam que nas últimas décadas da sociedade escravocrata a escrita da política antinegro alcançou todo o horizonte do território brasileiro.

Nos textos "Cidades Negras no Brasil: Cidadania e Território" e "Segregação Racial e Desigualdades Urbanas nas Cidades Brasileiras: Elementos para uma observação da necropolítica" (OLIVEIRA, 2020), analiso exatamente a questão das desigualdades e da segregação racial nas cidades, em específico, destaco que a segregação está inscrita no chão das urbes que se apresentam com as maiores representações absoluta e relativa de população negra, nas capitais e nas pequenas e médias cidades. Portanto, reitero a necessidade dos estudos e pesquisas que façam a 
interseccionalidade entre espaço, território, políticas públicas, lugar e relações étnico raciais no Brasil.

Nesse século XXI, se a reprodução da segregação socioeconômica permanecer destacando as desigualdades de classe social, nossas cidades continuarão reproduzindo espaços da pobreza negra, o genocídio negro, as extensas periferias habitadas por negros e pobres, e a sobrerepresentação nas ocupações e lugares de menor remuneração socioeconômica, portanto, os corpos de homens e mulheres negras permanecerão em evidência na violência e marginalização.

A sociedade reproduzindo a segregação de base socioeconômica, o resultado será a ampliação dos benefícios e desenvolvimento da branquidade nos principais espaços e lugares das cidades brasileiras (PATERNIANI, 2019; OLIVEIRA, 2015; 2016). Segundo Stella Paterniani (2019), da abolição aos dias de hoje, o quadro social da branquidade refletiu sempre em vantagens socioeconômica, cultural e política para a população branca nas cidades brasileiras, sobretudo em São Paulo.

No decorrer do texto, além das observações sobre territórios, territorialidade e segregação racial na urbe paulistana, apresento importantes avanços sobre o quadro das relações étnicas e raciais, como a questão da branquidade. O problema da segregação de base étnico racial não é uma questão específica da população negra, é de todos, brancos, indígenas, negros, populações de origem asiática, como japoneses e chineses, e os descendentes da imigração europeia, os portugueses, italianos, alemães, de todas as culturas e povos que vivem e fazem a história e a contemporaneidade das pólís desse século XXI.

A seguir, o texto está organizado em três etapas: a primeira, destaco as principais referências sobre a segregação étnico racial na cidade de São Paulo, como as dissertações e teses produzidas sobre a temática.

Posteriormente, na segunda etapa, interpreto o território negro na história da capital paulistana, o passado e o quadro atual. A terceira etapa, por meio de dados socioeconômicos dos Censos do IBGE, de 2000 e 2010, analiso a segregação e as desigualdades entre brancos e negros na capital paulistana. Observo a seguinte questão: Na passagem de uma década para outra, houve avanço ou não da segregação racial?

Por último, trago as considerações finais: Retifico a urgência de estruturar ideias para os lugares demasiadamente marcados por desigualdades étnico raciais e vice versa, 
os lugares de base étnico racial precisam de ideias para romper a lógica da cidade antinegra e da necropolítica.

\section{A PRODUÇÃO SOBRE ESPAÇO URBANO E RELAÇÕES ÉTNICAS RACIAIS}

Da pós-abolição aos dias de hoje, 132 anos, as cidades brasileiras receberam incipientes abordagens sobre o quadro étnico racial e a geografia, em geral, as ciências que se dedicam a observar a cidade e o urbano utilizaram a regra da interpretação socioeconômica.

Portanto, as cidades brasileiras foram observadas a partir das referências da Escola Francesa de Estudos Urbanos de Orientação Marxista (EFESUM). De 1960 até o final do século XX, as observações teórico metodológicas desenvolveram interpretações sobre a espoliação urbana, a segregação socioeconômica, as periferias longínquas e desequipadas, a cidade "fora da lei", ou seja, estudos que reforçam o quadro social nas sociedades capitalistas em desenvolvimento (PACHECO, 1989). A ausência de estudos sobre as relações étnicas e raciais na sociedade brasileira, deve-se, as questões teórica metodológicas reiterando apenas o cenário socioeconômico, ao mito da igualdade racial que reforçava o cotidiano do paraíso racial entre brancos e negros.

Dentre as interpretações acima, o enfrentamento do mito da igualdade racial começou a sofrer enfrentamentos a partir dos anos de 1930, com maior envergadura em 1970. Na capital paulistana, nos idos de 1978, acontece a reorganização do movimento negro com a fundação do Movimento Negro Unificado - MNU. Nos últimos 42 anos, as reflexões e políticas empreendidas pelos atores que representam os movimentos sociais negros refletiram nas cidades brasileiras, como a organização social e política em torno dos territórios negros e do enfrentamento da segregação racial.

Conforme indicações no corpo do texto, os primeiros estudos receberam interpretações de Rolnik (1989), Amaral (1991) e Bernardo (1998). Posteriormente, nos primeiros anos do século XXI até o momento atual, dissertações e teses foram defendidas abordando o quadro urbano e as relações étnicas raciais de São Paulo

A dissertação de mestrado de João Carlos Gomes da Silva "Os suburbanos e a outra face da cidade: Negros em São Paulo 1900 a 1930”, focaliza os núcleos, bairros, lugares e posições ocupadas por homens e mulheres negras nas três primeiras décadas 
do século XX, como os bairros do Bexiga, Barra Funda, Sé e Sul da Sé. Em breve observação sobre as dissertações e teses sobre o tema, Silva (1990) inaugura os estudos sobre o negro e as cidades brasileiras.

Iniciei meus estudos e pesquisas abordando a cidade e as relações étnico raciais no ano de 1998, no curso de ciências sociais da PUCSP. Meu Trabalho de Conclusão de Curso versou sobre o bairro da Barra Funda, no passado era um território negro representado por espaços de moradia, trabalho e cultura, sobretudo as manifestações socioculturais em torno dos cordões e escolas de samba, posteriormente, com o grande dinamismo do capitalismo em solo paulistano, o bairro negro foi perdendo a sua força, ou seja, a população foi obrigada a migrar para além do Rio Tietê, nas primeiras periferias da zona norte da cidade.

No passado da urbe paulistana, a Barra Funda reunia homens e mulheres negros no universo do samba, ali no antigo lugar denominado Largo da Banana, no trabalho de assentar dormentes na ferrovia e a força do lupem proletariado negro no local e nas imediações, exercendo todo tipo de trabalho braçal.

Em 2002, defendi a dissertação “A Presença do Negro na cidade: Memória e Território da Casa Verde em São Paulo”, no Programa de Estudos Pós-Graduados em Ciências Sociais da PUC SP. O trabalho em questão destacou os territórios negros nas primeiras periferias da capital paulistana, na região norte, pós-Rio Tietê.

$\mathrm{Na}$ Casa Verde, me deparei com espaços sociais e culturais da população negra atuando no quadro da urbanização, como os terreiros de umbanda e candomblé, as escolas de samba, a Irmandade de São Benedito e a organização das famílias diante das dificuldades e do racismo.

Em 2006, dois trabalhos de doutorado foram defendidos abordando a temática. Maria Nilza da Silva, observou em sua obra "Nem para todos é a cidade: Segregação Urbana e Racial em São Paulo", os lugares e as posições que a população negra ocupa na sociedade sofrem o impacto da hierarquia das desigualdades socioeconômica, étnico racial e de gênero. Para a autora, a cidade não se apresenta para todos, sobretudo para a população negra, as oportunidades e os lugares de desenvolvimento são quase inexistentes, para ela são reservados os últimos lugares da cidade, nas periferias e espaços da marginalização social. A geógrafa Lourdes Carril, observou a cidade de São Paulo e as relações étnicas e raciais com outras olhares. Em "Quilombo, Favela e 
Periferias - A longa busca da cidadania”, a autora analisa o quadro social de jovens negros e pobres, moradores de bairros da zona sul da cidade e empreendedores da cultura hip-hop (canto, dança e grafite). Através do cenário social, como as moradias e o protagonismo de jovens negros na cultura do rap, a autora interpreta o importante papel político dos quilombos urbanos (favelas e periferias) diante da dinâmica da segregação racial de São Paulo.

Posteriormente, em 2008, diante dos resultados da dissertação de mestrado, dediquei-me a analisar a relação entre territórios negros e a segregação racial na urbe paulistana. Investiguei a cidade de São Paulo, focalizando os distritos da Cidade Tiradentes (49,80\%), Jardim Ângela (51,40\%) e Brasilândia (39,70\%), tidos como bairros de sobrerepresentação negra. Lembrando que nos anos 2000, a população negra paulistana representava, na época, 34\%. Nesses bairros, o percentual de negros ultrapassava a média da cidade.

Em diferentes momentos da cidade, os territórios e territorialidades, impediram o aprofundamento das desigualdades e da segregação, por intermédio das ações, reflexões e do material subjetivo: a produção de espaços do não-racismo, em torno do complexo quadro dos movimento sociais, como as organizações negras, os terreiros de umbanda e candomblé, a organização das mulheres negras, as irmandades do catolicismo negro, as artes e culturas negras, a organização dos estudantes do ensino médio e universitários negros, o movimento de jovens negros do movimento hip hop e mais recentemente o universo das redes sociais (meio digital e on line) de instituições, organizações sociais, canais e sites dedicados ao enfrentamento do racismo.

Jaime Amparo Alves, nos anos de 2008 e 2012, concluiu seus trabalhos de mestrado e doutorado, em ambos, o pesquisador abordou as questões em torno da articulação entre raça, violência estatal, vulnerabilidade social e espaço urbano na produção do que classifica geografia da morte. A geografia da morte, segundo o pesquisador, nas duas últimas décadas do século passado e o início do século XXI, refletiu, em maior proporção, nos distritos e bairros habitados pela população negra e pobre.

Os corpos negros, na história das cidades brasileiras estão presentes nas políticas e estratégias de dominação e morte. Nos 380 anos da sociedade escravocrata e, 
posteriormente, nos últimos 132 anos da sociedade do trabalho livre, a geografia da morte está relacionada às práticas de racismo e desigualdades de forma espacializada.

Em seguida, Danilo Sales do Nascimento França (2010), em "Raça, Classe e Segregação Residencial no município de São Paulo", por intermédio de dados estatísticos do Censo Demográfico do IBGE, de 2000, observa a segregação residencial, descrita a partir da articulação entre raça e classe social, em específico, dos negros nas classes médias e altas. Posteriormente, França (2017), em seu trabalho de doutorado, de forma comparativa analisa a segregação residencial dos negros e brancos das classes médias e altas da urbe paulistana, por intermédio dos dados dos Censos Demográficos do IBGE, de 2000 e 2010.

Mais recentemente, Stella Zagatto Paterniani (2019), em tese intitulada "São Paulo cidade negra: branquidade e afrofuturismo a partir de lutas por moradia", traz importantes contribuições para pensar a segregação étnica e racial a partir do olhar da branquidade, ou seja, dos benefícios e vantagens na história da cidade para a população branca, por exemplo, desde a lei de terras de 1850, a legislação da abolição e as inúmeras referências para a arquitetura e urbanização da cidade moderna.

De 1990 até o presente momento, dez produções científicas abordaram a cidade de São Paulo e as relações étnicas e raciais ${ }^{3}$. Os trabalhos apresentam avanços importantes para os estudos sobre a cidade e o urbano e as relações étnico raciais, no entanto, a recente literatura não refletiu, de forma direta, no quadro das políticas públicas de combate ao racismo e à segregação racial no âmbito local, estadual e nacional.

\section{TERRITÓRIOS E TERRITORIALIDADES NEGRAS EM QUESTÃO}

O conceito de território e territorialidade é interdisciplinar, abrange desde as ciências humanas, sociais aplicadas, ciências da saúde e exatas. Nas ciências humanas, as interpretações estão nos campos da antropologia, sociologia, ciência política, geografia, história, filosofia, portanto, é uma construção que requer o conhecimento crítico, interdisciplinar e de inúmeras interseccionalidades com os principais problemas

\footnotetext{
3 As referências acima são as que foram analisadas, para esse trabalho não foi possível fazer um levantamento abrangente das últimas décadas do século XX e do momento atual. Acredito que nos últimos 20 anos outros trabalhos foram observados, relacionando espaço urbano e raça na capital paulistana.
} 
da vida social, por exemplo, a cartografia de homicídios e feminicídios na urbe paulistana.

Nas ciências da saúde, o território pode ser interpretado a partir da leitura biopsisocial dos corpos de homens e mulheres, utilizados no nascimento do hospital, da clínica e dos espaços de prisão e aprisionamento. São os corpos negros, indígenas e dos insurgentes nas sociedades que passaram por colonização, escravismo e segregação racial, que tiveram a interferência direta e indireta das ciências que perfazem a ideia de território, como a psicologia, medicina, saúde coletiva, enfermagem, nutrição, dentre outras.

O território compreende inúmeras faces, dentre elas, a questão política perante a constituição de um Estado, requer a presença de uma área territorial, juntamente com o seu poder de força, organização e administração dos espaços físico, sociais e jurídicos. O território reúne uma série de características, do ponto de vista qualitativo e quantitativo: eles são elementos sociais, étnicos, religiosos, econômicos, políticos, subjetivos, biológicos, psíquicos, de determinado grupo humano que se encontra nos espaços das cidades, local e global.

Nas principais urbes do país, o território representa as expressões da demarcação de fronteiras de uma cidade, estado, lugar, enfim, de uma configuração que é geográfica, social e cultural. Na capital paulistana, o território se expressa nos lugares onde estão localizados, por exemplo: de um lado, o poder socioeconômico, como as Avenidas Paulista e a Luis Carlos Berrini (na zona sul) que são expressões do poder econômico; os bairros, ruas e avenidas que constituem os territórios da riqueza e da branquidade; de outro lado, os bairros e lugares onde estão as populações negras e de baixa renda.

A territorialidade é o resultado do comportamento, do modo de vida, das desigualdades, da cultura, das línguas e expressões de um grupo social. Na pólis paulistana, a territorialidade negra está inscrita na sociedade escravocrata, da pósabolição, da sociedade do trabalho livre, urbana industrial e de nossa atualidade, marcada pela presença do meio técnico científico informacional e em quase tudo que o ser humano precisa para viver a sociedade do século XXI (SANTOS, 1993, 2002).

Em “Territórios Negros nas Cidades Brasileiras (etnicidade e cidade em São Paulo e rio de Janeiro), Raquel Rolnik (1989), marca o início da produção nacional 
sobre o tema. Em seu estudo, a autora aborda nas duas urbes, o universo social da população negra no contexto urbano e rural, sobretudo do urbano das últimas décadas da sociedade escravocrata e os primeiros anos da sociedade do trabalho livre. Rolnik, ao observar as urbes, gradativamente, descreve os espaços, lugares e territórios que serviram de trabalho, moradia e resistência de homens e mulheres negras.

Teresinha Bernardo (1998), em "Memória em Branco e Preto: olhares sobre São Paulo", observa as diferenças étnico raciais nas primeiras décadas do século XX. A autora, a partir de fontes empíricas de italianos e seus descendentes e de homens e mulheres negras, constitui quatro olhares da capital paulistana: o do homem branco, a respeito da cidade do progresso e do desenvolvimento; o olhar da mulher branca, da urbe das oportunidades; o homem negro, a partir da falta de oportunidades no mercado de trabalho; e o quadro da mulher negra, referente às imagens da escuridão, porque no decorrer do desenvolvimento de São Paulo, os negros sempre se depararam com os espaços de moradia nos lugares mais distantes e da escuridão com a falta de energia.

Raul Joviano do Amaral (1991), dialoga de fora do âmbito acadêmico a concepção social do território negro. $\mathrm{O}$ autor constitui território e territorialidade negra a partir da história de seus antepassados, os homens e mulheres negras fundaram a Irmandade Nossa Senhora do Rosário dos Homens Pretos da Igreja do Paissandu, fundada em 1711. Há exatamente 309 anos, a Irmandade de Nossa Senhora do Rosário resiste às investidas da sociedade que mantem os benefícios para a branquidade, sobretudo da pós-abolição ao momento atual. A Irmandade Negra reúne em sua história parte da fundação e desenvolvimento da capital paulistana.

Na obra de Amaral, a cartografia negra está localizada nas seguintes direções: na região do triângulo financeiro das Ruas Direita, São Bento e Barão de Itapetininga; ali, está localizada parte da memória negra da cidade, como o espaço da Irmandade de Nossa Senhora do Rosário dos Homens Pretos (igreja, cemitério e as habitações); o Pelourinho e a Irmandade dos Remédios; na Rua da Liberdade, era o local de leilão de escravos; no Bexiga, existia o Quilombo do Saracura; na região sudeste, o percurso em direção ao Quilombo do Jabaquara e o caminho para o quilombo de Santos; e nos arredores da cidade, os negros conviviam nos casebres e chácaras (OLIVEIRA, 2002). Abaixo, brevemente, apresento os territórios e territorialidades negras no decorrer do século $\mathrm{XX}$, no chão da capital paulistana. 
O primeiro momento de 1890 a 1930, os bairros da Sé, Sul da Sé, Liberdade, Bexiga, Barra Funda e Santa Cecília, até as três primeiras décadas do século XX foram espaços sociais de trabalho e moradia de homens e mulheres negras na urbe paulistana. É o caso, por exemplo, da Barra Funda, ali, a população negra e italiana vivia nos cortiços e porões. Homens e mulheres negros diante da sociedade em desenvolvimento, exerciam todos os trabalhos manuais e de menor remuneração: eram ajudantes, carregadores de caixas e produtos diversos, faziam a troca de dormentes da linha férrea, as mulheres eram cozinheiras, cuidadoras de crianças, trabalhos de limpeza, dentre outros.

É importante destacar que a história dos bairros é ao mesmo tempo parte da história da cidade e vice versa. $\mathrm{O}$ bairro reúne a diversidade que forma o todo da cidade.

O bairro é um pedaço da cidade, um momento, um setor da forma e a sua natureza, constituída por parte e a sua imagem: uma unidade morfológica. Os bairros situam-se na metrópole com alguma autonomia e alguma dependência do todo e essa dupla realidade é sua característica fundamental, o jogo dialético da parte e do todo (VÉRAS, 1991; 146).

Fora dos espaços de subrepresentação socioeconômica, os negros estavam inseridos nas instituições sociais e culturais, como a Irmandade Nossa Senhora do Rosário dos Homens Pretos do Paissandu, nos blocos carnavalescos da Barra Funda, Bexiga, Santa Cecilia e Liberdade, enfim, nos espaços negros, as relações e a produção das identidades proporcionavam o desenvolvimento dos grupos, a ajuda mútua e o enfrentamento do racismo.

Posteriormente, o segundo momento de 1940 até o final dos anos 70, está relacionado com a expansão da cidade sempre em direção às primeiras periferias, na zona norte, os bairros da Casa Verde, Parque Peruche, Bairro do Limão e Imirim, gradativamente, foram sendo ocupados pela massa negra expulsa das regiões da Barra Funda, Liberdade, Bexiga, Santa Cecilia e arredores.

A questão da habitação na cidade de São Paulo foi um dos principais fenômenos do quadro social que motivou as transformações, principalmente o crescimento em direção às primeiras periferias. Conforme Nabil Bonduki (1998) a cidade cresce tendo como referência a autoconstrução dos loteamentos nas periferias distantes, construída nos finais de semana com a ajuda da família e dos amigos. Esta foi a regra do crescimento da urbe paulistana a partir dos anos de 1940 até o final do século XX. Hoje, 
São Paulo não tem para onde crescer de forma horizontal, apenas o crescimento vertical para a população de baixa renda nas periferias e nas áreas intermediárias e ricas, a verticalização de alto padrão, ou seja, a autossegregação.

Nesse mesmo período do nascimento das periferias, como os bairros negros da zona norte, parte deles foram motivados por intermédio da orientação que a Imprensa Negra divulgava em seus periódicos para a massa negra, ela incentivava sair dos porões e cortiços insalubres e seguir em direção às primeiras periferias (OLIVEIRA, 2002; 2008).

Até o final dos anos de 1960 e 1970, os bairros da Casa Verde, Parque Peruche, Bairro do Limão, na zona norte, eram locais certos de escolha para moradia da população negra, em razão do quadro socioeconômico e étnico racial.

A população local, sobretudo da Casa Verde, ali plantou no chão do território parte das principais insígnias negras. Gradualmente, mesmo com bruscas mudanças no local, como a valorização do espaço que provocou a venda de casas e terrenos para a população de maior poder aquisitivo. A força do território foi sustentando as referências históricas, sociais e identitárias, como os terreiros de candomblé e umbanda, a Irmandade de São Benedito, as escolas de samba Unidos do Peruche, Unidos da Casa Verde e a Império da Casa Verde. A força do território está no lugar das territorialidades no bairro da Casa Verde.

O terceiro momento, de 1970 até o momento 2010, está relacionado ao grande desenvolvimento da cidade de São Paulo, o protagonismo nacional na economia urbana industrial e o processo de globalização e liberalismo econômico que atingiu a maior parte das sociedades em desenvolvimento como o Brasil.

Nesse momento, a massa negra acompanha cada vez mais o movimento em direção aos limites da cidade. O movimento território desterritorialização e reterritorialização aconteceu em razão da política antinegro que se abateu sob a população negra, como a sobrerrepresentação na pobreza e o racismo estrutural, invisibilizado pelas representações da branquidade.

$\mathrm{Na}$ história do século XX, os territórios e territorialidades negras tiveram que se (re)organizar e diante da segregação e das políticas antinegro. Os distritos e bairros da Cidade Tiradentes, Jardim Ângela e Vila Brasilândia são exemplos do constante 
movimento da segregação racial diante dos territórios negros na história da cidade (OLIVEIRA, 2008; 2016).

As narrativas dos homens e mulheres negras desses territórios nas zonas leste, oeste e sul da cidade, reforçam, em diferentes momentos, nas vitórias e nos grandes enfrentamentos da vida, a resistência para manter o chão do território, como a busca da habitação nas periferias distantes, o trabalho nos lugares e posições fora dos padrões impostos pela sociedade.

Ao estudar os territórios e territorialidades negras da capital paulistana ao longo do século XX, o quadro se torna central na história da cidade: as gerações mais antigas, intermediárias e contemporâneas, inscreveram, cada um a seu tempo, quadros sociais do antirracismo; os espaços, lugares e territórios, gradativamente, foram desenhando faces da história e cultura afro-brasileira em solo paulistano; as bases da hierarquia das desigualdades socioeconômicas, étnico raciais e de gênero, foram questionadas pelos atores que vivem fora dos lugares e ideias dos pensamentos que ditam o crescimento e desenvolvimento da cidade e do urbano.

Os estudos sobre territórios negros cresceram potencialmente, destacando a complexidade material e subjetiva de homens e mulheres negra nas cidades brasileiras. Henrique Cunha $(2019 ; 2018)$ observa diferentes perspectivas de análise dos bairros negros nas cidades brasileiras. No bairro do Pelourinho, na cidade de Salvador, o bairro negro compreende o lugar de resistência, de turismo étnico e de lugar de extrema visibilidade na história da cidade global e multicultural. Na cidade de Embu das Artes, a ocupação do espaço pela população negra nos quadros da residência, da cultura e artes, teve o papel de transformar a urbanização local. A urbanização foi movida pela atuação cultural e política por um grupo de artistas, intelectuais e atores dos movimentos sociais negros, dentre eles, Solano Trindade, sua filha Raquel Trindade, seus familiares e amigos.

\section{SEGREGAÇÃO RACIAL EM SÃO PAULO}

Em 1900, a cidade de São Paulo não expressava todo o dinamismo do capitalismo nacional, sul-americano e global em solo paulistano. Conforme Milton Santos (1993), apenas quatro urbes estavam acima de cem mil habitantes em pleno 
limiar do século XX: inicialmente, a ex-capital federal, Rio de Janeiro, detinha 691.565 habitantes, posteriormente, a atual capital econômica, São Paulo, alcançava 239.820 pessoas, em seguida, a primeira capital do Brasil, Salvador, apresentava 205.813 indivíduos, a cidade de Recife, participava com 113.106 habitantes e a principal urbe da região norte, Belém, registrava 96.560 habitantes.

Passados 120 anos, São Paulo é a principal cidade do país, enquanto carro chefe da economia nacional. A cidade se fez protagonista a partir das bases do trabalho escravizado de africanos e afro-brasileiros, do início do escravismo até as três primeiras décadas do século XX. Em quase todas as pedras das cidades brasileiras, o legado da força de trabalho de homens e mulheres negras está presente, por exemplo; a edificação e construção de avenidas, ruas, linhas férreas, praças, habitações, igrejas, prédios públicos e privados, como as igrejas da Sé, do Mosteiro de São Bento e os elementos decorativos da fachada da Igreja da Ordem Terceira do Carmo, foram edificadas por Tebas, Joaquim Pinto de Oliveira (um negro arquiteto, em pleno século XVIII), que foi por mais de dois séculos invisibilizado pelas faces do racismo e da branquidade, seu legado foi excluído das principais reflexões sobre a cidade e o urbano no Brasil (FERREIRA, 2018).

Após a abolição até os dias de hoje, a força de homens e mulheres negras continua mantendo à frente o poderio econômico do país, da capital paulistana e das principais urbes brasileiras.

Conforme o último Censo Demográfico do IBGE 2010, a população negra ultrapassou a população branca em número de população. No país, os negros somam 50,94\% da população nacional, e em inúmeras cidades das regiões norte, nordeste, sudeste e centro oeste, a população negra ultrapassa a média nacional, como as cidades negras de Salvador (79,26\%) e Belo Horizonte (52,37\%), de outro lado, São Paulo e Rio de Janeiro, ambas representam outra face das cidades negras, em dados absolutos, a primeira conta com 4.164.505 habitantes negros e a segunda com 3.026.823 negros.

Na capital paulistana, conforme os censos de 1991, 2000 e 2010, negros e negras, em números relativo, alcançaram 27\%, 30\% e 37\% da população local. Os 4.164.505 habitantes negros estão distribuídos na urbe paulistana conforme os critérios de classe social, étnica raça, gênero e território, logo, a ocupação do espaço social não se apresenta de forma democrática, com direitos iguais à todos, brancos e negros. 
A segregação racial nas cidades brasileiras e, em particular, na urbe paulistana, está assentada no quadro da hierarquia das desigualdades, que distribui ricos e pobres, brancos e negros, desproporcionalmente nos lugares e espaços; de um lado, os brancos sobrerepresentados nas classes média e alta do quadrante sudoeste, de outro lado, os negros, em maior proporção nas favelas, cortiços e nas distantes periferias.

Nos textos, "Segregação Racial e Desigualdades Urbanas nas Cidades Brasileiras: Elementos para uma Observação da Necropolítica" e "Cidades Negras no Brasil: Territórios e Cidadania", apresento um quadro teórico sobre a segregação racial, apontando dez assertivas, dentre elas: destaco a política antinegro, constantemente desferida no chão da cidade nos últimos 132 anos, que teve como reflexo a manutenção da população negra sobrerepresentada na pobreza e a necropolítica, baseada em questões históricas e sociais de sociedades regidas fortemente por hierarquias de poder, que estabelece quem tem o direito de viver e morrer na sociedade contemporânea.

Observando as cartografias da população negra na cidade de São Paulo, mapas 1, 2 e 3 abaixo, é importante contextualizar os principais fatos da ocupação do espaço social: do pós abolição até o final do século XX, gradativamente, a política antinegro caracterizou que negras e negros ocupassem os lugares e territórios sem cidadãos; os espaços mais valorizados, desenvolvidos e urbanizados, foram reservados aos brancos e o inverso aconteceu para os negros, os espaços e lugares da pobreza e de precária urbanização; a massa negra está distribuída na cidade, porém, conforme o desenvolvimento da capitalismo nacional em solo paulistana, os negros sempre foram seguindo em direção aos últimos lugares da urbe, em direção aos extremos.

Os distritos da Brasilândia, Cidade Tiradentes e Jardim Ângela, localizados nos extremos da cidade, estão no referido contexto acima. No chão da cidade, a segregação racial está inscrita na história de vida dos homens e mulheres negras, das gerações mais antigas até as atuais. Na memória coletiva de homens e mulheres negras dos referidos distritos, observei a repetição e desenvolvimento das características étnico raciais e urbanas, apontadas por Teresinha Bernardo: para os homens e mulheres italianos e seus descendentes, a cidade do progresso e do desenvolvimento; para os homens e mulheres negras, a cidade da escuridão, da falta de oportunidades, das ocupações e lugares de sub-representação socioeconômica e política (BERNARDO, 1998; OLIVEIRA, 2016). 
O Mapa 3, Cartografia da População Negra na cidade de São Paulo, representa a última leitura demográfica da população no contexto local. A partir do terceiro mapa, reitero a assertiva acima, no decorrer do século XX, o percurso da população negra, manteve-se nos lugares, posições e territórios da pobreza e também corresponde ao percurso dos lugares e territórios, em maior proporção, ocupado pela população negra.

Mapas 1 e 2. Cartografia da População Negra na cidade de São Paulo, 1991 e 2000.
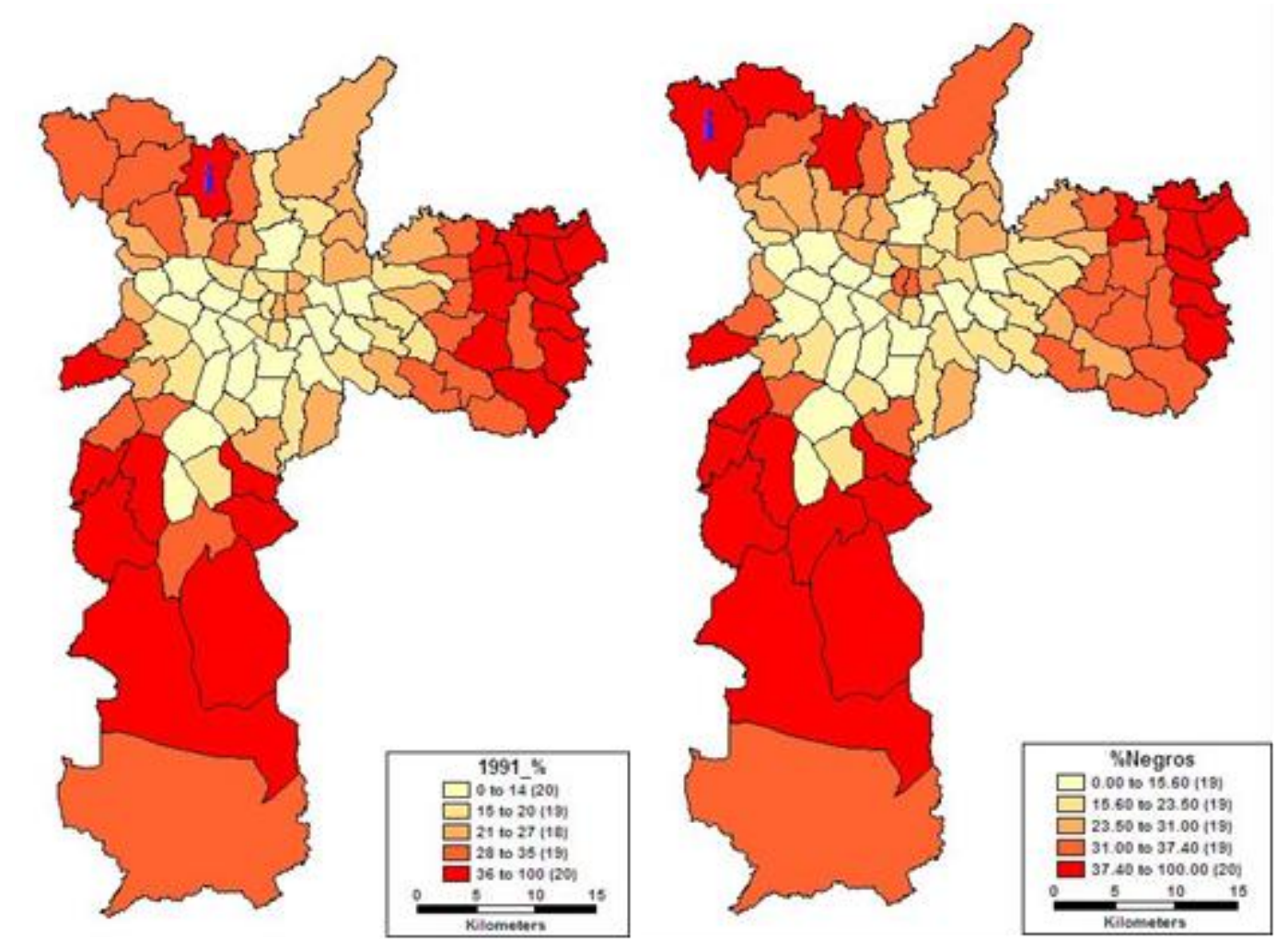

Fonte: Elaboração do autor.

Lendo as quatro cartografias, a intersecção entre classe social, etnia raça, gênero e território estão presentes na hierarquia das desigualdades, sobretudo da necropolítica, com a cartografia da geografia da morte no município de São Paulo. 
Conforme as tabelas 1 e 2 abaixo, a capital paulistana, de 2000 para 2010, cresceu em 817.950 mil habitantes. Na segunda para a terceira década do século XXI, a pólis paulistana é a única dentre as cidades brasileiras que se encontra acima dos 10 milhões de habitantes. Parte desse crescimento demográfico, deve-se ao quadro diverso da natalidade, ao deslocamento demográfico interno e externo, a sociedade urbana industrial e o cenário da globalização. Nesse cenário histórico e atual, a população negra, conforme as transformações do capital local e global, não teve outra opção; a segregação racial foi definindo os lugares e posições na pobreza, marginalidade e na hierarquia de poder.

Em 2000, a população branca totalizava 6.988.909 habitantes, dez anos depois, retrocedeu a 6.824.668 indivíduos. Houve um decréscimo de 164.241 pessoas classificadas como brancas. Dentre os negros, aconteceu o inverso, em 2000, a população negra correspondia a 3.133 .333 indivíduos, posteriormente, no censo de 2010, totalizou 4. 169.301 habitantes. No intervalor de dez anos, a população negra cresceu em 1.035.968 habitantes, diferente dos brancos, apresentou taxas elevadas de crescimento, mesmo com todo o quadro social das desigualdades étnico raciais.

Mapa 3. Cartografia da População Negra, 2010.

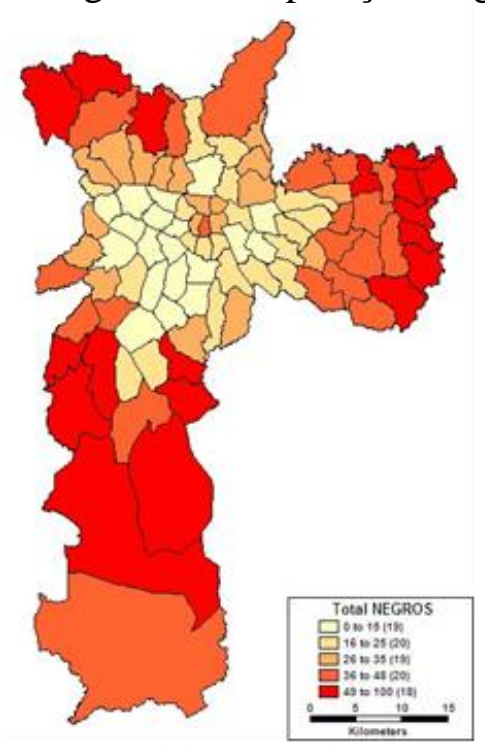

Fonte: Elaboração do autor.

Mapa 4. Cartografia dos Homicídios em São Paulo, 2014. 


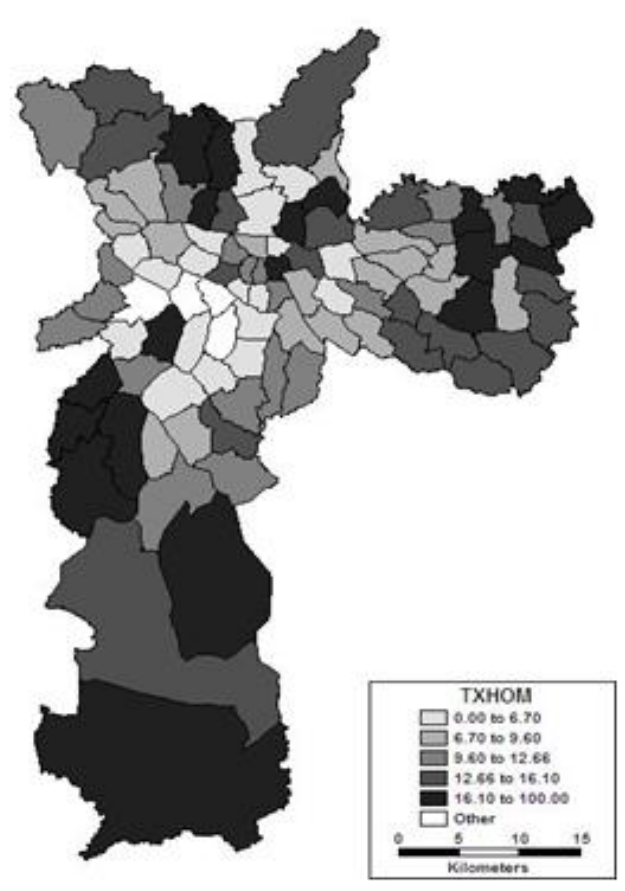

Fonte: Fundação Seade. Elaboração do autor. 
Tabela 1- População da cidade de São Paulo, classificada entre brancos e negros, 2000.

\begin{tabular}{|c|c|c|c|c|c|}
\hline & Total & Branca & Negra & Branca \% & Negra \% \\
\hline São Paulo & 10435553 & 6988909 & 3133313 & 67,00 & 30,00 \\
\hline Anhanguera & 38427 & 22592 & 15191 & 58,80 & 39,50 \\
\hline Brasilândia & 247328 & 144465 & 98103 & 58,40 & 39,70 \\
\hline Iguatemi & 101780 & 64385 & 36747 & 63,30 & 36,10 \\
\hline Vila Curuçá & 146483 & 78263 & 65651 & 53,40 & 44,80 \\
\hline Pedreira & 127424 & 68507 & 56499 & 53,80 & 44,30 \\
\hline Capão Redondo & 240793 & 127259 & 109681 & 52,80 & 45,50 \\
\hline Jardim Helena & 139107 & 70017 & 66914 & 50,30 & 48,10 \\
\hline Itaim Paulista & 212734 & 106765 & 103082 & 50,20 & 48,50 \\
\hline Cidade Tiradentes & 190657 & 94268 & 95037 & 49,40 & 49,80 \\
\hline Lajeado & 157773 & 73276 & 81663 & 46,40 & 51,80 \\
\hline Parelheiros & 102836 & 51120 & 49836 & 49,70 & 48,50 \\
\hline Grajaú & 334289 & 165946 & 163019 & 49,60 & 48,80 \\
\hline Jardim Ângela & 245806 & 116106 & 126285 & 47,20 & 51,40 \\
\hline
\end{tabular}

Tabela 2. Maiores Distritos com população negra classificados em ordem crescente (\%), 2010.

\begin{tabular}{|c|c|c|c|c|c|}
\hline & Total & Branca & Negra & Branca \% & Negra \% \\
\hline São Paulo & 11253503 & 6824668 & 4169301 & 60,64 & 37,05 \\
\hline Anhanguera & 65859 & 32358 & 33097 & 49,13 & 50,26 \\
\hline Brasilândia & 264918 & 128800 & 134049 & 48,62 & 50,60 \\
\hline Iguatemi & 127662 & 61822 & 64932 & 48,43 & 50,86 \\
\hline Vila Curuçá & 149053 & 71404 & 76329 & 47,91 & 51,20 \\
\hline Pedreira & 144317 & 67332 & 75682 & 46,66 & 52,45 \\
\hline Capão Redondo & 268729 & 121644 & 144843 & 45,27 & 53,90 \\
\hline Jardim Helena & 135043 & 60399 & 73905 & 44,73 & 54,73 \\
\hline Itaim Paulista & 224074 & 99761 & 122738 & 44,52 & 54,78 \\
\hline Cidade Tiradentes & 211501 & 91817 & 118586 & 43,41 & 56,06 \\
\hline Lajeado & 164512 & 71180 & 92374 & 43,27 & 56,15 \\
\hline Parelheiros & 131183 & 54739 & 74266 & 41,73 & 56,61 \\
\hline Grajaú & 360787 & 152873 & 204967 & 42,37 & 56,81 \\
\hline Jardim Ângela & 295434 & 115619 & 177578 & 39,14 & 60,01 \\
\hline
\end{tabular}

Fonte dos Dados: Banco SIDRA. Elaboração do autor.

Conforme as tabelas 1 e 2 acima, dos 96 distritos da cidade de São Paulo, os distritos da Brasilândia, Cidade Tiradentes, Jardim Ângela e àqueles com as maiores taxas de população negra, estão localizados, em maior proporção, na hierarquia das desigualdades de classe social, gênero, etnia raça e território. Os distritos das tabelas acima, apresentam percentual de população negra acima da média da cidade, de $37 \%$ a 
$60 \%$, como o Jardim Ângela, que totaliza as maiores taxas relativa e absoluta de homens e mulheres negras.

A interpretação das cartografias e tabelas subsidia a seguinte leitura dos territórios e da segregação racial na cidade de São Paulo: dos 96 distritos, em 34 a população negra está presente acima de 37\% até $60 \%$ (em 1/3 do território de São Paulo), portanto, os territórios e territorialidades, como os terreiros de umbanda e candomblé, as entidades negras, as organizações de mulheres negras, as associações de cultura e artes, o movimento hip hop e os coletivos de jovens negros, estão sobrerepresentados nas periferias e seus extremos; a segregação racial reflete na realidade espacial, socioeconômica e política da população negra na capital paulistana; a hierarquia das desigualdades impõe, entre brancos e negros, diferentes oportunidades em capital social, científico e cultural, referências importantes para o desenvolvimento da cidade.

Em 2010, o rendimento nominal médio do paulistano era de $\mathrm{R} \$ 1.296,58$ no universo da população em idade ativa. Entre homens e mulheres, brancos e negros, as desigualdades aparecem conforme o deslocamento das áreas desenvolvidas, urbanizadas e de maior poder aquisitivos branco, tende a alcançar os menores rendimento quando se aproxima dos extremos da cidade. Os homens recebiam, em média, $\mathrm{R} \$ 1.675,91$, as mulheres, R\$ 962,57, logo o gênero feminino recebia 57\% dos ganhos do seu par masculino.

Dentre brancos e negros, o aprofundamento das desigualdades e da segregação tem o seguinte quadro: em primeiro lugar, o homem branco recebe, em média, $\mathrm{R} \$$ 2.166,36, em segundo lugar, a mulher, $\mathrm{R} \$ 1.197,30$; em terceiro lugar, o homem negro recebe, em média, $\mathrm{R} \$ 863,42$, em último lugar, a mulher negra, seu rendimento nominal médio alcança $\mathrm{R} \$ 550,93$; a diferença proporcional do rendimento entre brancos e negros, perfaz a escala do homem branco à frente das mulheres branca e negra e do homem negro; a mulher branca recebe aproximadamente $50,27 \%$ do rendimento do branco, o homem negro, recebe entre $39,85 \%$ do rendimento do seu parceiro branco e a mulher negra, seu rendimento corresponde a $25,43 \%$ da rendimento nominal médio do homem branco.

Nos distritos e bairros negros, localizados nas periferias e seus extremos, o rendimento entre brancos e negros segue a hierarquia das desigualdades e da 
segregação: nos 34 distritos com maior participação negra, o branco pobre recebe alguns reais acima do rendimento dos homens e mulheres negras, mesmo na periferia sobressaem as vantagens da branquidade diante das oportunidades étnica raciais; nos distritos ricos e brancos, o rendimento dos negros corresponde a dados abaixo da média da cidade, por exemplo, no distrito do Morumbi, o homem negro recebe $13 \%$ do rendimento do homem branco e a mulher negra sobrevive com $10 \%$ do rendimento nominal médio do homem branco.

Tabela 3. Distritos classificados com as maiores taxas de negros, de brancos e renda.

\begin{tabular}{|l|l|l|l|l|}
\hline DISTRITO & COR/RAÇA & TOTAL & MASCULINO & FEMININO \\
\hline São Paulo & Total & 1296,58 & 1675,91 & 962,57 \\
\hline & Branca & 1642,07 & 2166,36 & 1197,30 \\
\hline & Negra & 702,86 & 863,42 & 550,99 \\
\hline Brasilândia & Total & 696,81 & 752,73 & 571,80 \\
\hline & Branco & 667,72 & 854,80 & 506,59 \\
\hline & Negro & 549,95 & 673,88 & 434,43 \\
\hline Cid.Tiradentes & Total & 492,34 & 615,27 & 383,94 \\
\hline & Branco & 513,52 & 652,07 & 396,70 \\
\hline Jd.Ângela & Negro & 501,24 & 607,70 & 403,65 \\
\hline & Total & 515,52 & 650,72 & 390,22 \\
\hline & Branca & 565,46 & 722,72 & 428,55 \\
\hline Moema & Negra & 506,52 & 626,82 & 383,53 \\
\hline & Total & 5420,85 & 7715,77 & 3562,31 \\
\hline & Branca & 5596,31 & 7925,21 & 3688,30 \\
\hline Morumbi & Negra & 2658,05 & 4187,70 & 1764,91 \\
\hline & Total & 4644,12 & 6699,96 & 2903,51 \\
\hline & Branca & 5593,92 & 8160,81 & 3433,95 \\
\hline Jd.Paulista & Preta & 963,32 & 1142,29 & 808,72 \\
\hline & Total & 5052,33 & 6902,60 & 3612,17 \\
\hline & Branca & 5337,33 & 7272,65 & 3818,63 \\
\hline Tatuapé & Negra & 2183,35 & 2997,06 & 1631,21 \\
\hline & Total & 2375,344 & 3224,14 & 1674,14 \\
\hline & Branca & 2452,85 & 3353,01 & 1721,96 \\
\hline & Negra & 1861,07 & 2478,14 & 1287,42 \\
\hline
\end{tabular}

Fonte dos Dados: Banco SIDRA, acesso em maio de 2020. Elaboração dos dados, o autor.

É importante lembrar que esse pedaço da cidade está em uma área valorizada, rica e de alta concentração de capital econômico, porém, nas imediações dos territórios da riqueza branca, está localizado o maior núcleo habitacional de baixa renda, a favela de Paraisópolis, os menores rendimentos de homens e mulheres negras estão localizados exatamente nesse território. No ano de 2019, em uma festa funk, promovida por jovens e adolescentes de Paraisópolis, nove jovens morreram em decorrência de uma ação policial que tinha como objetivo a perseguição e aprisionamento de traficantes de drogas que agem no território. No final, os corpos dos pobres, jovens e negros, foram 
dominados pela ação de dominação e extermínio por parte do Estado (política militar) no espaço urbano, que julga quem deve viver e quem deve morrer.

Nos distritos e bairros intermediários, como o Tatuapé, as classes médias e altas de brancos e negros se diferenciam na forma que a segregação residencial e a socioeconômica se expressam. Conforme França (2017), as classes médias e altas negras, mesmo compartilhando o mesmo território que as classes médias e altas brancas, circulam e vivenciam lugares e oportunidades distantes de seus vizinhos. Os brancos dos grupos socioeconômicos de maior poder aquisitivo, vivenciam espaços sociais que se estendem ao quadrante sudoeste, a área mais rica e de maior poderio em termos de desenvolvimento e urbanização. Para o grupo negro do mesmo segmento socioeconômico, as oportunidades no quadrante sudoeste não estão no mesmo patamar que seus vizinhos brancos alcançam.

No distrito do Tatuapé, as classes média e alta negra recebem, no grupo masculino, $51 \%$ dos rendimentos do homem branco e a mulher negra, aproximadamente, 38,39\% da renda do homem branco. Nas classes de menor poder aquisitivo, homens e mulheres negras estão sobrerepresentados no quadro socioeconômico, que tende a refletir em importantes espaços e lugares da vida social da cidade, por exemplo, a habitação e seu entorno, as oportunidades educacionais e a mobilidade urbana.

A população negra dos segmentos mais posicionados não escapa da segregação e da hierarquia das desigualdades na sociedade brasileira. Para os negros de melhor posição socioeconômica, o preço de uma trajetória de sucesso tem um peso forte na vida das pessoas, material e subjetiva, sobretudo no processo de formação e desenvolvimento das identidades. Nesse quadro, segundo Maria Nilza da Silva (1999), é a mulher negra que mais sofre, porque para adquirir sucesso, elas precisarão abrir mão de muitas coisas, por exemplo, do mercado matrimonial, abrir mão da maternidade, precisam encarar cotidianamente as desigualdades de classe, o machismo, o racismo e o sexismo, portanto, é uma carga material e subjetiva que provoca muitas dores nos corpos das mulheres negras e na estrutura da saúde mental.

Os territórios e territorialidades negras aqui abordados, como os distritos da Barra Funda, Casa Verde, Brasilândia, Cidade Tiradentes e Jardim Ângela, são os mesmos atores que Abdias do Nascimento dialogou nas cenas públicas do Rio de 
Janeiro (1978). Na ex-capital federal, os territórios e territorialidades negras se desenvolveram na geografia dos morros, favelas e no subúrbio carioca. Na geografia do Rio de Janeiro, a segregação racial coloca em campos opostos os espaços da riqueza branca da zona sul versus os espaços das favelas, comunidades e habitações autoconstruídas por negros e pobres. Portanto, na capital paulistana, na capital carioca e nas cidades negras do país, a população negra é protagonista das forças que sedimentam os territórios e territorialidades.

Segundo Milton Santos (2006), a força do lugar está presente no corpo social dos territórios e territorialidades, local e global. Nas sociedades em desenvolvimento, onde impera a herança do escravismo e é fortemente cravada pela segregação, nesse caso é o tempo lento dos atores que vivem e fazem a transformação do território, por intermédio dos instrumentos sociais e culturais que representam a força do lugar.

A pobreza negra e a classe média negra, ambas, precisarão se aproximar, tendo em vista trocar, aprender e transformar os espaços e a segregação das cidades brasileiras.

Em “Dialética Radical do Brasil Negro”, Clóvis Moura (1994), contextualiza o papel das classes sociais negras diante das desigualdades e do racismo. Para o autor, os grupos de letrados e iletrados, o primeiro é formado pelos homens e mulheres negras que alcançaram oportunidades e desenvolvimento intelectual com a educação, e o segundo, diz respeito à massa negra que está presente nos territórios e territorialidades negras que se localizam nos morros, favelas, nas comunidades das periferias autoconstruídas por eles mesmos.

Nos territórios e territorialidades negras em constante transformação, acredito que parte do avanço, provavelmente, seja da relação dos grupos negros que formam a massa negra e os grupos de desenvolvimento intelectual, ambos, devem se complementar, dialogar e romper as estruturas que separam brancos e negros. Por que na passagem das décadas de 2000 e 2010, a segregação racial na cidade de São Paulo avançou?

\section{CONSIDERAÇÕES FINAIS}


Conforme as referências no decorrer do texto, a segregação racial resulta em benefícios e vantagens para determinados grupos nas cidades, na capital paulistana é a branquidade que se beneficia no quadro socioeconômico e político.

Após a finalização do último censo, 2010, a partir dos dados analisados, confirmei que a segregação de base racial na cidade de São Paulo avançou, entre brancos e negros (OLIVEIRA, 2016). O avanço da segregação étnico racial configurase em fortalecimento da hierarquia e das desigualdades que separam brancos e negros na capital paulistana: a consolidação dos distritos, lugares e posições das classes sociais brancas nas áreas mais desenvolvidas, ricas e urbanizadas do quadrante sudoeste; nas periferias distantes, nas favelas e nos conjuntos habitacionais de baixa renda, a massa negra tem se concentrado sempre de forma crescente; nos últimos 132 anos, os territórios e territorialidades negras, gradativamente, impediram o avanço da política antinegro e da necropolítica em relação aos corpos de homens e mulheres negras; a população negra foi mantida nos lugares e posições da pobreza e da marginalidade social.

Em 2017, a tese defendida por França, reitera os meus argumentos sobre o avanço da segregação racial entre brancos e negros na capital paulistana, como os lugares e posições das classes média e alta brancas e negras.

Entre 2018 e 2019, em pesquisas realizadas pela Rede Nossa São Paulo e o Ibope, novamente, reiteraram o avanço da segregação racial na cidade de São Paulo, sobretudo as distâncias espaciais, socioeconômica, política e cultural entre brancos e negros.

Portanto, meus estudos de 2008 e 2016, a tese de França (2017) e as pesquisas da Rede Nossa São Paulo, (2018; 2019) confirmam o avanço da segregação racial na cidade de São Paulo, sobretudo na perspectiva da sobrerepresentação negra nos espaços, lugares e territórios da pobreza e da marginalização.

$\mathrm{O}$ enfrentamento, creio que deve seguir no percurso que caracteriza a política antinegro e da necropolítica. As forças que estão à frente dos poderes, União, estados e municípios, independente da posição política, de esquerda, centro e direita, pouco e/ou quase nada, responderam para enfrentar o quadro da segregação racial no século XX e nos dias de hoje. 
Os poderes institucionais, no que toca às políticas públicas, não estabeleceram políticas de Estado para enfrentar a segregação de base racial. As políticas públicas empreendidas não abordam o racismo estrutural, simplesmente refletem apenas no quadro socioeconômico que reproduz as vantagens da branquidade.

Após a aprovação da legislação de cunho étnico racial, como as leis 10.639/2003, 11.645/2008, o Estatuto da Igualdade Racial e o Programa Nacional de Saúde Integral da População Negra, brancos e negros precisarão problematizar as questões aqui focalizadas, diante da urgência da realidade e dos estudos empreendidos, pautar nas agendas governamentais políticas de estado para o enfrentamento da segregação racial.

\section{REFERÊNCIAS}

ALVES, Jaime do Amparo . Macabre Spatialities: the politics of race, gender and violence in a neoliberal city. Tese de Doutorado em Antropologia Social, Universidade do Texas, Austim, EUA, 2012.

ALVES, Jaime do Amparo. Spatialization of Death: Black Youth, Police, and Resistance in a Sao Paulo's Shantytown. Dissertação em Antropologia Social, Universidade do Texas, Austim, EUA, 2008.

AMARAL, Raul Joviano do. Os pretos do Rosário de São Paulo - subsídios históricos, segunda edição, João Scotercci Editora, São Paulo, 1991.

BERNARDO, Teresinha. Memória em Branco e Negro: olhares sobre São Paulo. São Paulo, Educ e Editora da Unesp, 1998.

BONDUKI, Nabil. Origens da habitação social no Brasil: arquitetura moderna, lei do inquilinato e difusão da casa própria. São Paulo, Estação Liberdade, 1998.

CARRIL, Lourdes. Quilombo, Favela e Periferia - A longa busca da cidadania. São Paulo, Annablume, Fapesp, 2006.

CUNHA JR., Henrique. Bairros Negros: a forma urbana das populações negras no Brasil. Revista da ABPN, número 11, 2019, p.65-86.

FERREIRA, Abílio (org.) Tebas, um negro arquiteto na São Paulo escravocrata. São Paulo, IDEA, 2018.

FRANÇA, Danilo Sales do Nascimento. Raça, Classe e Segregação Residencial no município de São Paulo. Dissertação de Mestrado em Ciências Sociais, CSO, USP, 2010.

FRANÇA, Danilo Sales do Nascimento. Segregação Racial em São Paulo: residências, redes pessoas e trajetórias urbanas de negros e brancos no século XXI. Tese de Doutorado, Faculdade de Filosofia, Letras e Humanas, USP, 2017. 
IBGE, Instituto Brasileiro de Geografia e Estatística. Censos Demográficos de 2000 e 2010. Brasília, 2020.

MBEMBE, Achille. Necropolítica. Rio de Janeiro, Revista Arte e Ensaio, n.32, 2016.

MOURA, Clóvis. Dialética Radical do Brasil Negro. São Paulo, Editora Anita, 1994.

NASCIMENTO, Abdias. O Genocídio do Negro Brasileiro - processo de um racismo mascarado. Rio de Janeiro, 1978.

OLIVEIRA, Reinaldo José de (organizador). A Cidade e o Negro no Brasil: Cidadania e Território. São Paulo, Editora Alameda, 2013.

. A Presença do Negro na Cidade: Memória e Territorialidade da Casa Verde em São Paulo. Dissertação de Mestrado em Ciências Sociais, PUC SP, 2002.

A segregação urbana e racial avançou no Brasil? In: Relações etincorraciais e educação escolar indígena: relatos de pesquisa. Vitória da Conquista, Edições UESB, 2017.

. Novos e Antigos cenários da Segregação e das Desigualdades da População Negra em São Paulo. In: Desigualdades urbanas, Segregação, Alteridade e Tensões em Cidades Brasileiras, Maura Pardini Bicudo Véras (organizadora), Judiai, SP, Paco Editorial, 2018.

. O Sol nasceu pra todos, a sombra apenas para os brancos: segregação urbana e racial nas cidades brasileiras. In: Dilemas da Raça - Empoderamento e Resistência. São Paulo, Editora Alameda, 2017.

. Territorialidade Negra e Segregação Racial na cidade de São Paulo - A luta por cidadania no século XX. São Paulo, Editora Alameda, 2016.

OLIVEIRA, Reginaldo José de e OLIVEIRA, Regina Marques de Souza. Origens da segregação racial no Brasil,, Amérique Latine Histoire et Mémoire. Les Cahiers ALHIM [En línea], 29|2015, Publicado el 18 junio 2015, consultado el 15 junio 2020. URL: http://journals.openedition.org/alhim/5191

PACHECO, Regina Silvia e LEME, Maria Cristina Silva. A Questão fundiária, imobiliária e os serviços urbanos: conceitos e referências teóricas em teses e dissertações recentes. Revista Espaço e Debates, número 28, 1989.

PATERNNIARI, Stela Zagatto. São Paulo cidade negra: branquidade e afrofuturismo a partir de lutas por moradia. Tese de Doutorado, Programa de Pós-Graduação em Antropologia Social, UNB, 2019.

REDE NOSSA SÃO PAULO, Viver em São Paulo, Relações Raciais. São Paulo, 2018; 2019.

ROLNIK, Raquel. A Cidade e a lei - legislação, política urbana e território na cidade de São Paulo, Editora Nobel, 1997.

ROLNIK, Raquel. Territórios Negros nas Cidades Brasileiras (etnicidade e cidade em São Paulo e Rio de Janeiro), in: Revista de Estudos Afro-Asiáticos, Rio de Janeiro, Cadernos Cândido Mendes, número 17, setembro de 1989.

SANTOS, Milton Santos. A Natureza do espaço - técnica e tempo, razão e emoção. São Paulo, EDUSP, 2006.

A Urbanização Brasileira. São Paulo, Editora Hucitec, 1993.

Revista da ABPN • v. 12, n. $34 \cdot$ Set - Nov 2020, p.489-515 
SILVA, Maria Nilza da. Nem para todos é a cidade: segregação urbana e racial em São Paulo. Brasília: Fundação Cultural Palmares, 2006.

SOUZA, Regina Marques de; OLIVEIRA, Reinaldo José de. Corpos em Cena nas Metrópoles globais: Meninas negras, processos de subjetivação e cinema. Revista da Associação Brasileira de Pesquisadores/as negros/as (ABPN), v. 7, n.15, p. 175-191, fev. 2015. ISSN 2177-2770. Disponível em: 〈https://abpnrevista.org.br/index.php/site/article/view/120>. Acesso em: 17 set. 2020

TELLES, Edward. Racismo à Brasileira - Uma nova perspectiva sociológica. Rio de Janeiro, Editora Relume Dumará, 2003.

VÉRAS, Maura Pardini. O bairro do Brás em São Paulo. Um século de transformações do espaço urbano ou diferentes versões da segregação social. Tese de Doutorado em Ciências Sociais, PUC SP, 1991.

Recebido em: 22/09/2020

Aceito em: 30/10/2020 